heat treatment is about $24 \mu \mathrm{ohmcm}$. The change of resistance with temperature depends very much on the heat treatment given. For the above heat treatment the change from room temperature to $100^{\circ} \mathrm{C}$ will be about 1.5 per cent. For about 2 hours ageing at $250^{\circ} \mathrm{C}$ the change over this temperature interval is very small.

Tested against a moving cupro-nickel substrate with a contact force of $15 \mathrm{~g}$, the contact resistance was 10 milliohms. This value was reproducible since the standard deviation of 12 results was 2.1 milliohms.

The solderability of the alloy was very dependent upon ageing time. Tests showed the solderability of the fully aged material to be poor compared with pure gold, but in practice soldered joints could be made easily by hand.

For the heat treatment given above the hardness is about 270 Vickers. The 0.1 per cent proof stress for this heat treatment is $620 \mathrm{MN} / \mathrm{m}^{2}\left(40.1\right.$ tonf $\left./ \mathrm{in}^{2}\right)$ and the ultimate tensile strength is $690 \mathrm{MN} / \mathrm{m}^{2}(44.7$ tonf $\left./ \mathrm{in}^{2}\right)$. Elongation has not been determined.
Brittleness results from too high a solution treatment temperature or from excessive grain growth.

\section{Conclusion}

A gold alloy has been developed which because of its response to precipitation heat treatment can be made particularly suitable as a sliding contact. It is hard, strong, and wear-resistant, has a low contact resistance and resistivity and at room temperature it is completely tarnish-resistant. The temperature coefficient of resistance is well characterised and in some heat treatment conditions can be made very low or zero for temperature fluctuations around ambient.

\section{References}

1 H. C. Angus, Trans. Inst. Metal Finishing, 1962, 39, 1

2 E. M. Wise, "Gold", D. van Nostrand Co, New York, 1964

3 R. Holm, "Electric Contacts", Springer Verlag, Berlin 1967

4 E. Raub, Z. Metallkunde, 1960, 51, 290

\title{
Gold Brazing in the Space Shuttle Engines
}

The production of the three main engines for the space shuttle is now nearing completion by the Rocketdyne Division of Rockwell International at Canoga Park, California, under a contract from the National Aeronautics and Space Administration. While a number of joints are electron-beam or tungsten-arc welded, many thousands of assemblies have been furnace brazed in a hydrogen atmosphere with several types of gold brazing alloys to ensure high strength and resistance to corrosion.

Inconel 625 was chosen for a number of components, including the main injection elements, and these were brazed with $70 \mathrm{Au}-22 \mathrm{Ni}-8 \mathrm{Pd}$ alloy, while the $304 \mathrm{~L}$ stainless steel parts of the injector face plate were previously sub-assembled by brazing with $50 \mathrm{Au}-25$ Ni-25 Pd alloy.

The nozzle assembly is constructed from 1086 tapered and shaped tubes in a high nickel austenitic stainless steel, brazed together as a unit and supported by bands of Inconel 718 with Inconel 903 structural rings. Ageing cycles to develop the full properties of these alloys imposed the need for several stages of brazing at various temperatures, the alloys used ranging from $70 \mathrm{Au}-22 \mathrm{Ni}-8 \mathrm{Pd}$ to $18 \mathrm{Au}-25 \mathrm{Mn}-6 \mathrm{Pd}-6 \mathrm{Ni}-45$ $\mathrm{Cu}$. Over 15 pounds of these alloys were used to join more than 10,000 feet of tubing to the Inconel jacket, with a further 2160 brazed joints where the tube ends were attached to the manifold.

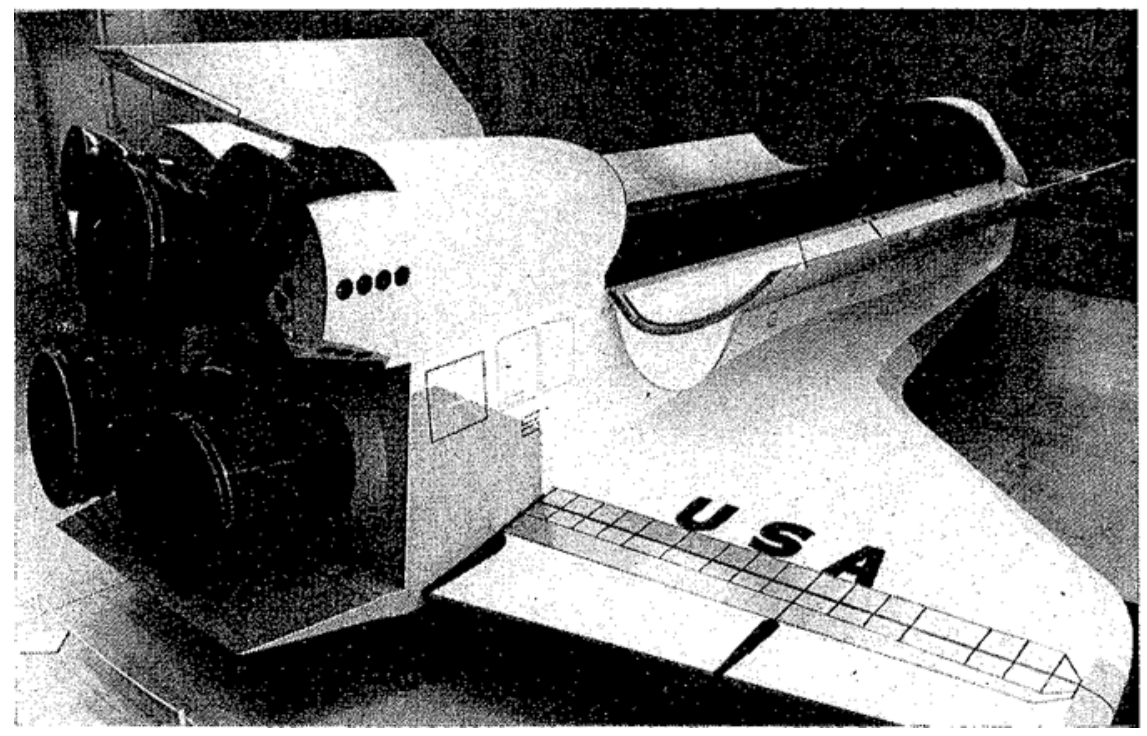

A full-scale mock-up of the space shuttle orbiter, a winged, manned vehicle about the size of a DC9 aircraft. Gold alloy brazing has been used extensively in the assembly of the three main engines 